\title{
Clinical Parameters for the Diagnosis of ASD
}

\author{
Aderbal Sabrá, Joseph Bellanti, Luciana Corsini, Aderbal Sabrá Filho, and Selma Sabra
}

\begin{abstract}
Autism spectrum disorder (ASD) is characterized by disorders of neurological development, typically diagnosed within the first 4 years of life, clinically presents with impairment in social interaction, deficits in verbal and nonverbal communication, and repetitive and purposeless stereotypic behaviors. One thousand of pre-diagnosed ASD patients, randomly selected, to be part of this study, where attended at the Unidade de Gastroenterologia, Alergia Alimentar e Autismo (UGAAA) at Unigranrio University, School of Medicine. This evolutionary report aims to evaluate the presence of the 6 most common clinical disorders of neurological development in ASD patients, selected to be the core for the table for the diagnosis of ASD.

Index Terms-autism spectrum disorder; objective evaluation of ASD; social interaction.
\end{abstract}

\section{INTRODUCTION}

The autistic spectrum disorder (ASD) is a neurodevelopmental disorder, typically diagnosed within the first four years of life, which clinically presents with persistent impairment in social interaction, deficits in verbal and non-verbal communication and repetitive purposeless behavior [1-4]. It occurs in one out of 68 individuals and can affect any child regardless of sex, race or socioeconomic status and is four to five times more frequent in males [5].

As we can see in figure one there are a overlap of time between the beginning of the ASD and the diagnosis. Several factors could be involved in this delay but most prominent are the difficulties of the pediatricians to recognize the disease ( and the absence of a score easily to be used by the doctor.

A major effort of this paper is to summarize those two parameters in one score easily done by the pediatrician during his clinical interview dealing with this problem.

Existing forms for evaluation of ASD are too extensive to be filled by the physician at the time of a medical appointment. And due to the need to evaluate the possible diagnosis of ASD, we structured a table for objective evaluation. This table was based in the most frequent complaints on the occasion of the first medical appointment by over 1000 patients with this disorder treated at UGAAA. (Figure 1).

The 6 most frequent complaints were: verbal communication, eye contact, social interaction, sleep, restrictive and repetitive behaviors and activity level. This evaluation was performed at any time according to the availability of return of the patients who undergo

Published on April 09, 2020.

A. Sabrá, Unigranrio School of Medicine, Brasil.

(corresponding e-mail: aderbalsabra@globo.com).

J. Bellanti, Georgetown University, USA.

L. Corsini, Unigranrio School of Medicine, Brasil

A. Sabrá Filho, Unigranrio School of Medicine, Brasil.

S. Selma, Unigranrio School of Medicine, Brasil. ambulatory follow-up.

\section{VERBAL COMMUNICATION}

Individuals with ASD tend to have unique and atypical acoustic patterns in speech. These behaviors affect social interactions and social development and may represent a non-invasive marker of ASD. Functional neuroimaging and electroencephalography recent studies demonstrate that aberrant voice processing could be a promising marker to identify ASD early [6].

We propose in our scale 4 steps in verbal communication: 1-do not speak or babble words; 2-echolalia or words out of context; 3-babble or speak words with context and 4-speak sentences.

\section{EYE CONTACT}

Patients with ASD tend to avoid eye contact [7-9]. In our scale we propose four steps for eye interaction: 1-patients tend to avoid eye contact; 2-did so sporadically; 3-patients make eye contact only after tactile, visual or auditory stimulation or 4-patients could have frequent and spontaneous eye contact.

\section{SOCIAL INTERACTION}

Deficits in communication and impairments in social interaction are main characteristics of children and adolescents with ASD. Children with ASD have less social skills [10], are more often victims of bullying [11] and spend less time interacting with others. [12-15]

In our evaluation we select four steps in the main scale for interaction: 1-no social interaction; 2-interaction only with family members; 3-interaction with strangers and 4-good social interaction with everyone.

\section{SLEEP}

Between 2 and 3 years of age there are long periods of nocturnal sleep followed by one or two daytime naps not exceeding a total of 2 hours. At age 3, usually only the afternoon siesta takes place. At 5 years of age, nocturnal sleep should already be fully consolidated, with no more nocturnal awakenings or need for daytime naps [6-9,16-18]. Only between 5 and 10 years of age a gradual decrease of the total time in nocturnal sleep occurs. In adolescence, nocturnal sleep reduction (mean of 7 hours) tends to occur, ranging from 8.6 to 6.4 hours from 14 to 16 years of age. [19] Children 3 to 5 years of age should sleep from 10 to 13 hours for 24 hours (including naps), children from 6 to 12 years of age should sleep from 9 to 12 hours for 24 hours, adolescents from 13 to 18 years of age should sleep 8 to 10 hours for 24 hours. [20] 
In our scale we propose the next evaluation: 1-patients slept less than $4 \mathrm{~h}$ a day, 2-slept less than $7 \mathrm{~h}$ per night and had sleep interruptions, 3-slept more than $7 \mathrm{~h}$ per night also with interruptions and 4-could sleep more than $7 \mathrm{~h}$ of continuous sleep, despite of large portion of patients making use of hypnotics, sleep inducers, anxiolytics and sedatives.

\begin{tabular}{|c|c|c|c|c|}
\hline SPEECH & $\begin{array}{c}\text { DO NOT SPEAK OR } \\
\text { BABBLE WORDS }\end{array}$ & $\begin{array}{l}\text { ECHOLALLA OR WORDS } \\
\text { OUT OF CONTEXT }\end{array}$ & $\begin{array}{l}\text { BABBLE OR SPEAK WORDS } \\
\text { WTTH CONTEXT }\end{array}$ & SPEAK SENTENCES \\
\hline $\begin{array}{l}\text { SOCIAL } \\
\text { INTERACTION }\end{array}$ & NO INTERACTION & $\begin{array}{l}\text { INTERACTS WITH } \\
\text { FAMILY ONLY }\end{array}$ & $\begin{array}{l}\text { INTERACTS WITH } \\
\text { STRANGERS }\end{array}$ & $\begin{array}{l}\text { GOOD INTERACTION } \\
\text { WITH EVERYONE }\end{array}$ \\
\hline EYE CONTACT & NEVER & OCCASIONALLY & $\begin{array}{l}\text { AFTER TACTILE, VISUAL OR } \\
\text { AUDTORY STIMULATIOON }\end{array}$ & $\begin{array}{l}\text { FREQUENT AND } \\
\text { SPONTANEOUS }\end{array}$ \\
\hline $\begin{array}{l}\text { LEVEL OF } \\
\text { ACTIVITY }\end{array}$ & CATATONIC & HYPOACTIVE & HYPERACTIVE & REGULAR \\
\hline SLEEP & $<4 W D A Y$ & $\begin{array}{l}\text { STWDAY WTH } \\
\text { INTERRUPTIONS }\end{array}$ & $\begin{array}{l}\text { >TWDAY WTH } \\
\text { INTERRUPTIONS }\end{array}$ & $\begin{array}{l}\text { >7hDAY CONTINUOUS } \\
\text { SLEEP }\end{array}$ \\
\hline $\begin{array}{l}\text { RESTRICTED AND } \\
\text { REPEITIIVE } \\
\text { BEHAVIOURS }\end{array}$ & CONSTANT & OCCASIONALLY & RARE & $\begin{array}{l}\text { NO STEREOTYPIC } \\
\text { BEHAVIORS }\end{array}$ \\
\hline
\end{tabular}

Fig. 1. Table for the diagnosis of patients with ASD, to be completed by the physician at the time of the outpatient visit. Based on the existing assessment and focusing on the six most frequent complaints of patients with the disorder.

\section{RESTRICTIVE AND REPETITIVE BEHAVIORS}

Although considerable progress has been made in understanding the underlying mechanisms of social and communicative impairments in ASD, the neurofunctional architecture of repetitive and stereotyped behaviors as well as other cognitive conditions related to response and action control remain poorly understood [21].

We select four steps regards restrictive and repetitive behaviors: 1-patients with constantly restrictive and repetitive behaviors, 2-patients with occasionally restrictive and repetitive behaviors, 3-rarely and 4-patients did not present that kind of behavior.

\section{ACTIVITY LEVEL}

Autism and catatonia have common symptoms such as mutism, echolalia, stereotyped speech and repetitive behaviors, postures, facial mimics, stiffness, mannerisms, and purposeless agitation [22]. Comorbidities such as hyperactivity, impulsivity and attention deficit occur in $41 \%$ to $78 \%$ of children with ASD $[23,24]$.

We grade our level of activity in those 4 steps: 1-patients in catatonic state; 2-patients hypoactive; 3-patients hyperactive, and 4-patients with regular activity level.

We propose in our scale 4 steps for each one of the selected 6 most frequent complaints: verbal communication, eye contact, social interaction, sleep, restrictive and repetitive behaviors and activity level.

Each step for the six more frequent complain is diagnosed in our patient. According to the next scale each level get a number. The somatorium of all six diagnosed complain could go from zero to 18 . In our experience less than 12 points after the application of the scale is suggestive of ASD.

Pontuation: Level 1 equal to zero points

Level 2 equal to one point

Level 3 equal to two points

Level 4 equal to tree points

\section{CONCLUSION}

Based on the six most frequent complaints of about 1,000 patients previously included in the ASD spectrum, who were diagnosed at the UGAAA, the table proposed for the diagnose of ASD is a useful tool to be used by all physicians dealing with the diagnosis of patients in the spectrum of ASD.

\section{REFERENCES}

[1] Amaral DG, Schumann CM, Nordahl CW Neuroanatomy of autism. Trends Neurosci. 2008; 31: 137-45

[2] Acosta MT, Pearl PL The neurobiology of autism: new pieces of the puzzle. Curr Neurol Neurosci Rep. 2003; 3: 149-56

[3] Geschwind, D.H. Advances in autism. Annu. Rev. Med. 2009, 60, 367-380.

[4] American Psychiatric Association. Dsm-5 Task Force (2013). Diagnostic and Statistical Manual of Mental Disorders: DSM-5.

[5] "Prevalence of Autism Spectrum Disorder Among Children Aged 8 Years - Autism and Developmental Disabilities Monitoring Network, 11 Sites, United States, 2010." Centers for Disease Control and Prevention, 28 Mar 2014. Web 25 May 2015.

[6] "Is voice a marker for Autism spectrum disorder? A systematic review and meta-analysis". Autism Res. 2016 Aug 8. [Epub ahead of print]

[7] Senju A, Johnson MH. Atypical eye contact in autism: models, mechanisms and development. Neurosci Biobehav Rev. 2009 Sep; 33(8):1204-14

[8] Infant neural sensitivity to dynamic eye gaze is associated with later emerging autism. Elsabbagh M, Mercure E, Hudry K, Chandler S, Pasco G, Charman T, Pickles A, Baron-Cohen S, Bolton P, Johnson MH, BASIS Team. Curr Biol. 2012 Feb 21; 22(4):338-42.

[9] Attention to eyes is present but in decline in 2-6-month-old infants later diagnosed with autism. Jones W, Klin A. Nature. 2013 Dec 19; 504(7480):427-31

[10] Macintosh K, Dissanayake C (2006) Social skills and problem behaviours in school aged children with high-functioning autism and Asperger's disorder. J Autism Dev Disord 36:1065-1076

[11] Cappadocia MC, Weiss JA, Pepler D (2012) Bullying experiences among children and youth with autism spectrum disorders. J Autism Dev Disord 42:266-277

[12] McConnell SR (2002) Interventions to facilitate social interaction for young children with autism: Review of available research and recommendations for educational intervention and future research. $\mathrm{J}$ Autism Dev Disord 32:351-372

[13] Locke J, Ishijima EH, Kasari C, London N (2010) Loneliness, friendship quality and the social networks of adolescents with highfunctioning autism in an inclusive school setting. J Res Spec Educ Needs 10:74-81

[14] Kasari C, Locke J, Gulsrud A, Rotheram-Fuller E (2011) Social networks and friendships at school: comparing children with and without ASD. J Autism Dev Disord 41:533-544

[15] Deckers A1, Muris P2, Roelofs J2.Being on Your Own or Feeling Lonely? Loneliness and Other Social Variables in Youths with Autism Spectrum Disorders. Child Psychiatry Hum Dev. 2017 Jan 9.[Epub ahead of print]

[16] Dahl RE, Carskadon MA. Sleep and its disorders in adolescence. In: Ferber R, Kryger M, editors. Principles and practice of sleep medicine in the child. Philadelphia: W. B. Saunders; 1995. p. 19-27.

[17] Wolfson AR. Sleeping patterns of children and adolescents, developmental trends, disruption and adaptations. Chil Adolesc Psychiatr Clin North Am. 1996;5:549-68.

[18] Anders TF, Sadeh A, Apparedy V. Normal sleep in neonates and children. In: Ferber R, Kryger M, editors. Principles and practice of sleep medicine in the child. Philadelphia: W. B. Saunders; 1995. p. 718.

[19] Iglowstein I, Jenni OG, Molinari L, Largo RH. Sleep duration from infancy to adolescence: reference values and generational trends. Pediatrics. 2003;111:302-7.

[20] Recommended Amount of Sleep for Pediatric Populations: A Consensus Statement of the American Academy of Sleep Medicine. J Clin Sleep Med. 2016 Jun 15;12(6):785-6.

[21] Chmielewski W. X. \& Beste C. Action control processes in autism spectrum disorder - Insights from a neurobiological and neuroanatomical perspective. Prog. Neurobiol. 124, 49-83 (2015). 
[22] Catatonia and autism: a historical review, with implications for electroconvulsive therapy. Dhossche DM, Reti IM, Wachtel LE. J ECT. 2009 Mar; 25(1):19-22.

[23] Murray MJ. Attention-deficit/hyperactivity disorder in the context of autism spectrum disorders. Curr Psychiatry Rep. 2010;12(5):382-388

[24] Attention-deficit/ hyperactivity disorder in autism spectrum disorders. Montiel-Nava C, Peña JA. Invest Clin. 2011 Jun; 52(2):195-204 